\title{
The Treatment of Becker's Nevus by Combination Therapy: Dr. Hoon Hur's Golden Parameter Therapy and Dr. HOON Hur's Optimal Melanocytic Suicide-1 Parameter Therapy
}

\author{
Hoon Hur*, Jie Hoon Kim, Duck Taik Shim, Suk Jin Choi, Pyoung Su Kim, Yu Ri Kim \\ Choice Dermatology Clinic, Pyeongchon, Korea \\ Email address: \\ dermahur@naver.com (H. Hur) \\ ${ }^{*}$ Corresponding author \\ To cite this article: \\ Hoon Hur, Jie Hoon Kim, Duck Taik Shim, Suk Jin Choi, Pyoung Su Kim, Yu Ri Kim. The Treatment of Becker's Nevus by Combination \\ Therapy: Dr. Hoon Hur's Golden Parameter Therapy and Dr. Hoon Hur's Optimal Melanocytic Suicide-1 Parameter Therapy. Journal of \\ Surgery. Vol. 9, No. 1, 2021, pp. 16-21. doi: 10.11648/j.js.20210901.13
}

Received: December 30, 2020; Accepted: January 19, 2021; Published: January 25, 2021

\begin{abstract}
Becker's nevus, a cutaneous hamartoma, usually occurs as a large, unilateral, hyperpigmented and hypertrichotic patch on the shoulder or upper trunk, which can be present in childhood or adolescence. Becker's nevus can be treated with traditional laser therapy using various types of lasers including a 532nm potassium titanyl phosphate (KTP) laser, 694nm ruby laser and 755nm alexandrite laser. However, this may cause harmful side effects such as scarring, mottled hypopigmentation, post-inflammatory hyperpigmentation (PIH), purpurae, and crusts. As a result, no standard for the treatment of Becker's nevus using lasers has been established. Therefore, this study was implemented to investigate the safety and efficacy of treating Becker's nevus using Dr. Hoon Hur's Golden Parameter Therapy (GPT) followed by Dr. Hoon Hur's Optimal Melanocytic Suicide-1 Parameter Therapy (OMS-1 PT) which uses a high fluence 1064nm Q-switched Nd: YAG laser (QSNL). Forty-two Koreans suffering from Becker's nevus participated in the study and received treatment on a weekly basis for 75-100 sessions using the QSNL according to Dr. Hoon Hur's GPT then followed by Dr. Hoon Hur's OMS-1 PT. The parameters for this study were a spot size of $7 \mathrm{~mm}$, a fluence of $2.2 \mathrm{~J} / \mathrm{cm}^{2}$ and a pulse rate of $10 \mathrm{~Hz}$ using a sliding-stacking technique for a single pass over the Becker's nevus, followed by Dr. Hoon Hur's OMS1 PT using a sliding technique for 5 passes with the QSNL over the Becker's nevus. Upon completion of the last treatment, all 42 patients with Becker's nevus were cured, having no side effects, and entirely removing the pigmented lesions. None of the 42 patients reported any recurrences after their follow-ups 6-15 months after the final treatment. As a result of this study, we propose therapy to safely and effectively treat Becker's nevus using a fusion of Dr. Hoon Hur's GPT and Dr. Hoon Hur's OMS-1 PT with a high fluence $1064 \mathrm{~nm}$ QSNL to avoid any recurrences or harmful side effects.
\end{abstract}

Keywords: Becker's Nevus, 1064nm Nd: YAG Laser, Dr. Hoon Hur's GPT, Dr. Hoon Hur OMS-1 PT

\section{Introduction}

Becker's nevus, a benign cutaneous pigmentary hamartoma with a localized hypertrichosis, may occur on the shoulder or upper trunk, occasionally elsewhere on the body during childhood or adolescence [1-3]. The histopathologic findings demonstrate that there is no nevus cell in the basal layer of epidermis and in the dermis and Becker's nevus does not develop into malignant lesion [3, 4]. Treatment for Becker's nevus may not be necessary except for cosmetic purposes. Moreover, Becker's nevus is not easy to cure without side effects and recurrences because a non-selective photothermolysis occurs during laser irradiation [5-7]. Therefore, this study was performed to confirm the efficacy and safety of Dr. Hoon Hur's Golden Parameter Therapy (GPT) and subsequently Dr. Hoon Hur's Optimal Melanocytic Suicide-1 Parameter Therapy (OMS-1 PT) with a high fluence $1064 \mathrm{~nm}$ Q-switched Nd: YAG laser (QSNL) for the treatment of Becker's nevus without inducing any side effects and recurrences.

\section{Objectives}

Treatment of Becker's nevus with traditional laser 
therapies including 532nm potassium titanyl phosphate (KTP) laser, $694 \mathrm{~nm}$ ruby laser and $755 \mathrm{~nm}$ alexandrite laser may cause harmful side effects such as purpurae, crusts, postinflammatory hyperpigmentation (PIH), mottled hypopigmentation and scarring. Unfortunately, therefore there has been no clear standard established for the laser treatment of Becker's nevus. Therefore, this study was conducted to investigate the efficacy and safety of Dr. Hoon Hur's Golden Parameter Therapy (GPT) and subsequently Dr. Hoon Hur's Optimal Melanocytic Suicide-1 Parameter Therapy (OMS-1 PT) with a high fluence 1064nm Qswitched $\mathrm{Nd}$ : YAG laser (QSNL) for the treatment of Becker's nevus.

\section{Materials and Methods}

A total of forty-two Korean patients (age range: 7-38 years old, mean age: 16.3 years old) with no significant medical or familial history who were clinically diagnosed with Becker's nevus (Figures 1, 4, 6, 8) were participated in this study. Written consents were received from all of the patients before undergoing this laser treatment. Before this laser treatment, 9.6\% lidocaine cream of topical anesthetics was not applied on the Becker's nevus. The patients were received 75-100 treatment sessions of Dr. Hoon Hur's GPT including a high fluence 1064nm QSNL (StarWalker Laser, Fotona, Slovenia) on a weekly basis with a spot size of $7 \mathrm{~mm}$, a fluence of $2.2 \mathrm{~J} / \mathrm{cm}^{2}$ and a pulse rate of $10 \mathrm{~Hz}$ with one pass by a slidingstacking technique over the Becker's nevus, and subsequently Dr. Hoon Hur's OMS-1 PT with 5 passes by a sliding technique using a high fluence $1064 \mathrm{~nm}$ Q-switched Nd: YAG laser (QSNL) over the Becker's nevus.

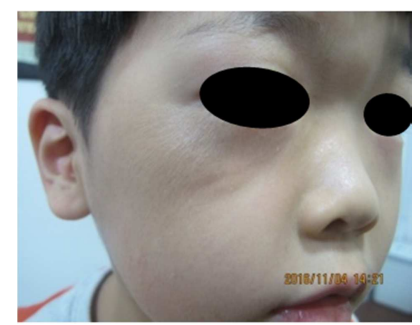

Figure 1. Becker's nevus on the right side of the face (before treatment: 2016/11/4).

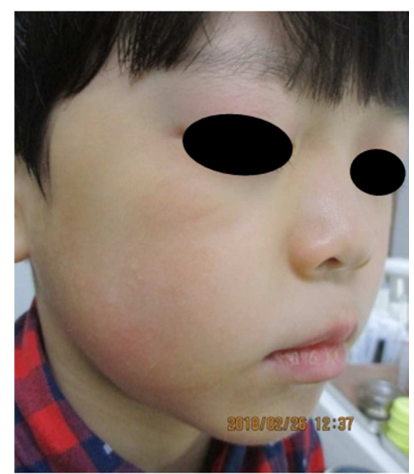

Figure 2. A complete clearance of Becker's nevus (after treatment with Dr. Hoon Hur's GPT and Dr. Hoon Hur's OMS-1 PT: 2018/2/26).

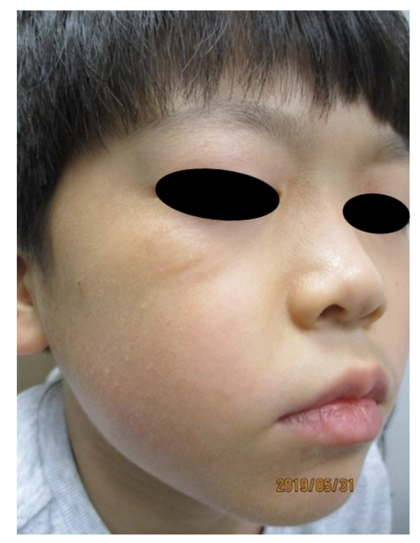

Figure 3. There is no recurrence at 15 months'follow-up. (2019/5/31).

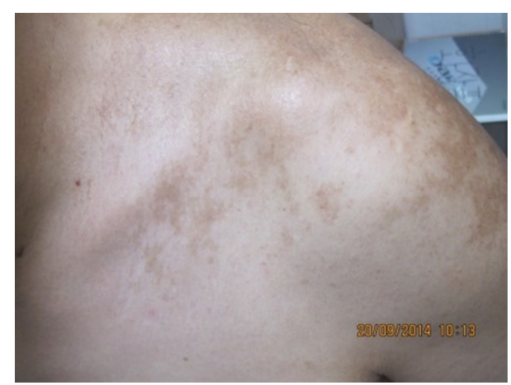

Figure 4. Becker's nevus on the left side of the upper chest (before treatment).

Post-each laser treatment, the lesion of Becker's nevus was cooled with ice packs but the broad-spectrum sunscreen cream was not used. To evaluate the result, photos taken on the first day of the treatment were compared to those taken 4 weeks after the final treatment session and these standardized digital photography were produced by a Canon Camera G11 (Japan). The physician's clinical assessment of the degree of improvement of the patients (mean score of two investigators who did not attend the treatment) was also conducted 4 weeks after the last treatment session and reported as percentage resolution as follows: poor $(0-25 \%$ clearance $)$, fair $(26-50 \%$ clearance $)$, good (51-75\% clearance), excellent (76-95\% clearance) and complete (96-100\% clearance) by analyzing the clinical photographs of patients. The patients were asked to report any side effects, pain or discomfort during the laser treatment.

\section{Results}

Forty-two Korean patients who suffer from Becker's nevus were participated in this study (Table 1 and Table 2). All of the 42 patients with Becker's nevus were achieved the complete clearance of the pigmented lesions (Figures 2, 5, 7, 9). There were no side effects reported such as purpurae, crusts, PIH, mottled hypopigmentation or scarring except mild pain during this laser treatment. No recurrences have been observed after a follow-up of 6-15 months (Figure 3). All patients, given combination therapy of Dr. Hoon Hur's GPT and Dr. Hoon Hur's OMS-1 PT using a high fluence 1064 $\mathrm{nm}$ QSNL were satisfied with the outcome of the therapy. 
Table 1. The demographic data of 42 patients with Becker's nevus and the characteristics of Becker's nevus.

\begin{tabular}{ll}
\hline Demographic data & \\
\hline Age & $7-38$ years old \\
Age range & 16.3 years old \\
Mean age & \\
Gender & $30 / 42(71.4 \%)$ \\
Male & $12 / 42(28.6 \%)$ \\
Female & $(-) ;$ unremarkable \\
Family history & \\
Location & $4 / 42(9.5 \%)$ \\
Face & $25 / 42(59.5 \%)$ \\
shoulder & $8 / 42(19 \%)$ \\
chest & $3 / 42(7.1 \%)$ \\
Thigh & $2 / 42(4.8 \%)$ \\
Lower leg & \\
Characteristics of lesion & $42 / 42(100 \%)$ \\
Brown pigmentation & $36 / 42(87.5 \%)$ \\
Follicular accentuation & $32 / 42(76.2 \%)$ \\
Hairy lesion & \\
\hline
\end{tabular}

Table 2. The result of treatment with Dr. Hoon Hur's GPT and Dr. Hoon Hur's OMS-1 PT.

\begin{tabular}{ll}
\hline Treatment response & Number of patients \\
\hline Poor $(0-25 \%$ clearance $)$ & 0 \\
Fair $(26-50 \%$ clearance $)$ & 0 \\
Good $(51-75 \%$ clearance $)$ & 0 \\
Excellent $(76-95 \%$ clearance $)$ & 0 \\
Complete $(96-100 \%$ clearance $)$ & $42 / 42(100 \%)$ \\
\hline
\end{tabular}

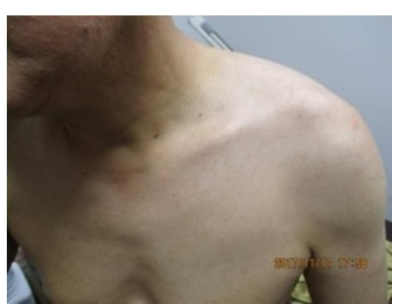

Figure 5. A complete clearance of Becker's nevus (after treatment with Dr Hoon Hur's GPT and Dr. Hoon Hur's OMS-1 PT).

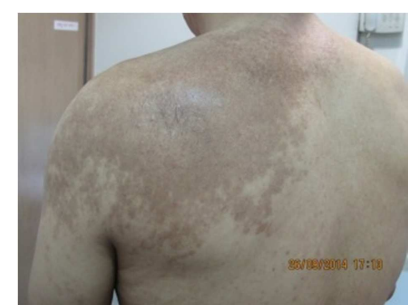

Figure 6. Becker's nevus on the left shoulder (before treatment).

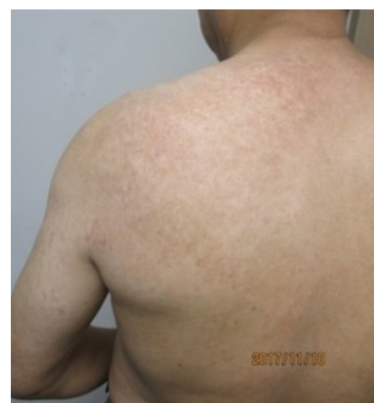

Figure 7. A complete clearance of Becker's nevus (after treatment with Dr. Hoon Hur's GPT and Dr. Hoon Hur's OMS-1 PT).

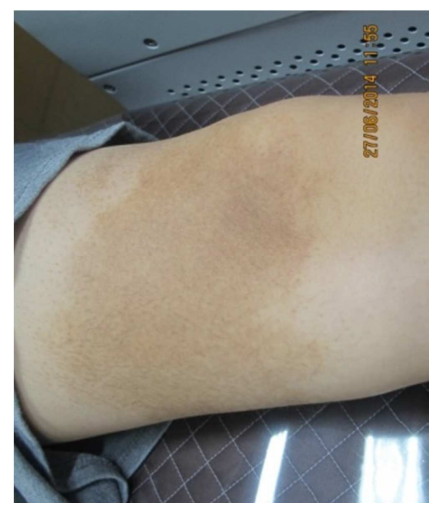

Figure 8. Becker's nevus on the left thigh (before treatment).

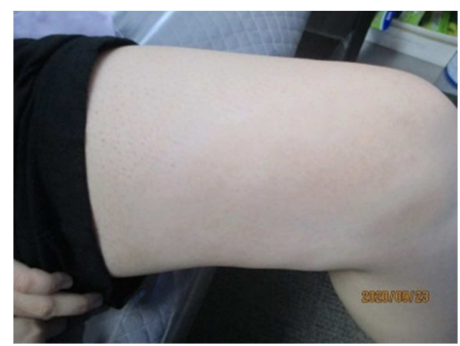

Figure 9. A complete clearance of Becker's nevus (after treatment with Dr. Hoon Hur's GPT and Dr. Hoon Hur's OMS-1 PT).

\section{Discussion}

A Becker nevus, a benign cutaneous hamartoma, is caused by overgrowth of the epidermis, epidermal melanocytes, hair follicles and dermal smooth muscles. It typically occurs as a unilateral, large brown hyperpigmented and hypertrichotic patch on the shoulders or upper trunk, occasionally elsewhere on the body, with onset in early adulthood, usually during or shortly after puberty [1-3]. It might appear in males at puberty because of gene defect and circulating androgens [8]. Becker's nevus can be easily diagnosed clinically but sometimes a biopsy may be required in order to differentiate the lesions from congenital melanocytic nevus and congenital smooth muscle hamartoma [3, 4]. In order to distinguish it from congenital melanocytic nevus and congenital smooth muscle hamartoma, it is very essential to figure out whether the lesion was present at birth or developed subsequently. Congenital melanocytic nevus is present at birth and typically darker in color with no anatomic predilection, therefore demonstrating melanocytic nevus cells on skin biopsy [3,20]. Congenital smooth muscle hamartoma typically presents at birth or infancy as a firm skin-colored or light brown plaque with less prominent pigmentation includes more localized hypertrichosis compared to Becker's nevus. Moreover, in most cases, pseudo-Darier's sign with temporary induration after rubbing the lesion is observed. Histologically, congenital smooth muscle hamartoma is characterized by the hyperplasia of smooth muscle bundles throughout the dermis $[3,4]$. The histopathological findings of Becker's nevus represents that moderate elongation and focal fusion of rete ridges with increased number of melanocytes and enhanced melanin deposition in the epidermis, and increased number of 
arrector pili muscles and the hyperplasia of smooth muscles in the dermis. Becker's nevus does not develop into a malignant lesion due to the non-presence of nevus cell $[3,4]$. Lately, Becker's nevus has been widely treated using traditional laser treatment involving a $694 \mathrm{~nm}$ ruby laser, $755 \mathrm{~nm}$ alexandrite laser, and $532 \mathrm{~nm}$ potassium titanyl phosphate (KTP) laser. Unfortunately these treatments are often looked at as rather unsatisfactory due to their possibility of negative side effects including scarring, mottled hypopigmentation, PIH, purpurae, and crusts [5-7]. In particular, Becker's nevus is quite difficult to cure without inciting PIH [5-7]. Disappointing outcomes for Becker's nevus using traditional laser therapy may have a few potential reasons. Normally, the melanin absorbs the 1064 $\mathrm{nm}$ wavelength of the QSNL much less than the $532 \mathrm{~nm}$ wavelength of the KTP laser, the $694 \mathrm{~nm}$ wavelength of the ruby laser, the $515-755 \mathrm{~nm}$ wavelength of intense pulsed light, and the $755 \mathrm{~nm}$ wavelength of the alexandrite laser [57]. This higher absorption by traditional therapy lasers creates laser energy, not only destroying epidermal melanocytes but also simultaneously damaging the surrounding keratinocytes contained within the lesions [5-7]. This causes the damaged keratinocytes to excrete interleukin1 (IL-1), thus stimulating the keratinocytes to excrete prostaglandin (PGE2, PGF2 $\alpha$ ), endothelin-1, adrenocorticotropic hormone (ACTH), and $\alpha$-melanocyte stimulating hormone (MSH), all of which are keratinocytic injury-induced cytokines. Unfortunately these melanogenic cytokines activate melanocytes, enhancing the synthesis of melanin in the melanosomes, leading to the $\mathrm{PIH}$ and thus aggravating Becker's nevus [9-12]. Secretions of the singlechain urokinase type plasminogen activator (sc-uPA), from the damaged keratinocytes, convert plasminogen into plasmin, and basic fibroblast growth factor (bFGF) is excreted from these plasmin-stimulated keratinocytes. This bFGF activated the melanocytes, driving melanin synthesis in the melanosomes to increase, thus causing PIH [9-12]. The laser energy in tradition laser treatments has enough strength to damage mast cells, macrophages, lymphocytes, fibroblasts, and vascular endotheliums in the dermis as well as create purpurae and crusts simultaneously. In particular, the excretions of hepatocyte growth factor (HGF) and stem cell growth factor (SCF) from damaged fibroblasts stimulate the enhancement of melanin synthesis in the melanosomes from melanocytes, leading to PIH, thus aggravating Becker's nevus [9-12]. Lastly, the reactive oxygen species like free radical oxygen and peroxide or nitric oxide, having been produced by damaged keratinocytes, activates the melanocytes and strengthens melanin synthesis in the melanosomes, in time causing PIH and worsening Becker's nevus [9-12]. The authors devised a new combination therapy using a Dr. Hoon Hur's GPT and Dr. Hoon Hur's OMS-1 PT with a high fluence 1064nm QSNL (StarWalker Laser, Fotona, Slovenia). With the parameters being a spot size of $7 \mathrm{~mm}$, a fluence of $2.2 \mathrm{~J} / \mathrm{cm}^{2}$, and a pulse rate of 10 $\mathrm{Hz}$, a sliding-stacking technique with a single pass above the Becker's nevus was done and subsequently Dr. Hoon Hur's
OMS-1 PT with 5 passes by a sliding technique with a high fluence1064nm QSNL over the Becker's nevus at intervals of one week. We believe that the combination therapy of Dr. Hoon Hur's GPT and Dr. Hoon Hur's OMS-1 PT using a high fluence $1064 \mathrm{~nm}$ QSNL is safer and more effective for the Becker's nevus treatment compared to traditional laser therapies. Authors from previous research papers claimed that treatment using Dr. Hoon Hur's GPT with a high 1064 nm QSNL was extremely effective and did not cause any harmful side effects such as scarring, PIH, or mottled hypopigmentation in other various pigmentary skin diseases including café au lait spots [12-16], Becker's nevus [13], partial unilateral lentiginosis [13, 17], Ota's nevus [18], Hori's nevus [19], congenital melanocytic nevus [20], Riehl's melanosis [21], erythema ab igne [22], and pruigo pigmentosa [23]. We surmise a fusion of Dr. Hoon Hur's GPT and Dr. Hoon Hur's OMS-1 PT, being performed routinely without damage to the epidermis on a weekly basis, leads to gradual destruction of epidermal melanocytes and dermal smooth muscles, therefore causing apoptotic melanocytic cell death program and apoptotic smooth muscle cell death program. Due to the poor absorption by epidermal melanin, Dr. Hoon Hur's GPT and Dr. Hoon Hur's OMS-1 PT with the adoption of high fluence $1064 \mathrm{~nm}$ QSNL is able to destroy the melanosomes in the epidermal melanocytes and dermal smooth muscles without epidermal damage, finally causing epidermal melanocytes and dermal smooth muscles to lose functions and turn into ghost cells [12-16]. Getting Dr. Hoon Hur's GPT and Dr. Hoon Hur's OMS-1 PT using a high fluence $1064 \mathrm{~nm}$ QSNL for a longer weekly basis using a high fluence $1064 \mathrm{~nm}$ QSNL destroys more epidermal melanocytes and dermal smooth muscles and promotes the apoptosis of epidermal melanocytes and dermal smooth muscles. Furthermore, both the end product of destroyed melanocytes and the dispersed melanins and melanosomes are eradicated by transepidermal elimination or by dermal melanophages through the lymphatic system [1216]. Normal melanocytes, which migrate from the outer root sheath of hair follicles by homeostasis and the apoptotic melanocytic cell death program, slowly replace the lesional melanocytes. And lastly, the removal of Becker's nevus can happen without incurring any side effects or recurrences [1216]. In this study, each of the 42 Becker's nevus patients were treated with 75-100 session of Dr. Hoon Hur's GPT using a high fluence $1064 \mathrm{~nm}$ QSNL, the spot size being $7 \mathrm{~mm}$, with a fluence of $2.2 \mathrm{~J} / \mathrm{cm}^{2}$ and a pulse rate of $10 \mathrm{~Hz}$ using a sliding-stacking technique with a single pass, followed by Dr. Hoon Hur's OMS-1 PT with 5 passes by a sliding technique with a high fluence1064 nm QSNL at a one-week interval. That said, Dr. Hoon Hur's GPT and Dr. Hoon Hur's OMS-1 PT with a high fluence 1064 nm QSNL does not create petechiae or purpurae, but induces erythema only. Since Dr. Hoon Hur's GPT and Dr. Hoon Hur's OMS-1 PT are less absorbed by epidermal melanin, they do not destroy normal background tissue but remove epidermal melanocytes and dermal smooth muscles without crusts and purpurae, eventually preventing $\mathrm{PIH}$ and scarring [12-16]. 
However, in order to remove Becker's nevus completely without recurrences, 75-100 continuous treatments are required on a weekly basis. In this study, all 42 patients with Becker's nevus (Figures 1, 4, 6, 8) were treated by Dr. Hoon Hur's GPT and Dr. Hoon Hur's OMS-1 PT with a high fluence $1064 \mathrm{~nm}$ QSNL. This complete removals of the pigmented lesions were accomplished without causing PIH and scarring in all 42 patients who suffer from Becker's nevus (Figures 2, 5, 7, 9). There was no relapse after 6-15 months of follow-up (Figure 3). All patients, given combination therapy of Dr. Hoon Hur's GPT and Dr. Hoon Hur's OMS-1 PT using a high fluence 1064 nm QSNL were satisfied with the outcome of the therapy.

\section{Conclusion}

This study included 42 patients with Becker's nevus, all of whom were treated using a fusion of Dr. Hoon Hur's Golden Parameter Therapy (GPT) and Dr. Hoon Hur's Optimal Melanocytic Suicide-1 Parameter Therapy (OMS-1 PT). The patients suffered from no harmful side effects and had no recurrences, and therefore were completely cured of Becker's nevus. It is our perspective that therapy using a fusion of Dr. Hoon Hur's GPT and Dr. Hoon Hur's OMS-1 PT with a high fluence $1064 \mathrm{~nm}$ QSNL is an effective, safe, and suitable treatment option for the complete removal of Becker's nevus.

\section{References}

[1] Glinick SE, Alper JC, Bogaars H, Brown JA. Becker's melanosis: Associated abnormalities. J Am Acad Dermatol 1983; 9: 509-13.

[2] Khaitan BK, Dogra D, Manchanda Y, Rathi S. Becker's nevus of the lower limb. Acta Derm Venereol (Stockh) 1998; 78: 238-9.

[3] AlGhamdi KM, AlKhalifah AI, AlSheikh AM, AlSaif FM. Clinicopathologic profile of Becker's melanosis with atypical features. J Drugs Dermatol 2009; 8: 745-8.

[4] Kim YJ, Roh MR, Lee JH, Na JI, Ko JY, Jung JM, Lee JH, Chang SE (2018) Clinicopathologic characteristics of earlyonset Becker's nevus in Korean children and adolescents. Int J Dermatol. 57: 55-61.

[5] Trelles MA, Allones I, Moreno-Arias GA, Vélez M (2005) Becker's nevus: a comparative study between erbium: YAG and Q-switched neodymium: YAG; clinical and histopathological findings. Br J Dermatol. 152: 308-13.

[6] Momen S, Mallipeddi R, Al-Niaimi F. The use of lasers in Becker's nevus: An evidence-based review. J Cosmet Laser Ther. August, 2016; 18 (4): 188-192.

[7] Polder KD, Landau JM, Vergilis-Kalner IJ, Goldberg LH, Friedman PM, Bruce S. Laser eradication of pigmented lesions: a review. Dermatol Surg. 2011; May: 37 (5): 572-95.

[8] J. R. Person and C. Longcope, "Becker's nevus: an androgenmediated hyperplasia with increased androgen receptors," $J$ Am Acad Dermatol. 1984; 10 (2): 235-238.
[9] Hattori H, Kawashima M, Ichikawa Y, Imokawa G. The epidermal stem cell factor is over-expressed in lentigo senilis: implication for the mechanism of hyperpigmentation. J Invest Dermatol. 2004; 122: 1256-1265.

[10] Okazaki M, Yoshimura K, Suzuki Y. The mechanism of epidermal hyperpigmentation in cafe au lait macules of neurofibromatosis type 1 may be associated with dermal fibroblast- derived stem cell factor and hepatocyte growth factor. Bri J Dermatol. 2003; 148: 689-697.

[11] Okazaki M, Youshimura K, Uchida G. Epidermal hyperpigmentation in non-syndromic solitary cafe au lait macules may be associated with increased secreation of endothelin-1 by lesional keratinocytes. J Plastic Sur \& hand Sur. 2005; 39: 213-217.

[12] Hur H. The Treatment of Café Au Lait Spot Using Dr. Hoon Hur's Golden Parameter Therapy. J Dermatol Ther. 2016; 1: $1-4$.

[13] Hur H, Kim YR, Shim DT. The Treatment of Café Au Lait Spot, Partial Unilateral Lentiginosis and Becker's Nevus Using a High Fluence 1064nm Q-swithed Nd: YAG Laser. J Clin and Cosmet Dermatol. 2017; 1: 1-4.

[14] Baek JO, Park IJ, Lee KR, Ryu HR, Kim JS, Lee SK, Kim YR, Hur H. High-fluence 1064-nm Q-Switched Nd: YAG laser: Safe and effective treatment of café-au-lait macules in Asian patients. J Cosmet Dermatol. 2018; 17 (3): 380-384.

[15] Hur H, Kim JH, Park IJ, Park CH, Shim DT, et al. The New Treatment of Café Au Lait Spot Using Dr. Hoon Hur's Golden Parameter Therapy With a High Fluence 1064nm Q-Switched Nd: YAG Laser. 2018; Int J Cur Res. April: 10 (4): 68082668086.

[16] Hur H, Shim DT, Song SE, Kim PS, Hyun DN, Kim YR. The Treatment of Infantile Café Au Lait Spot Using Dr. Hoon Hur's Golden Parameter Therapy with a High Fluence 1064nm Q-Switched Nd: YAG Laser. J Clin Res Dermatol. 2 020; 7 (1): 1-5.

[17] Hur H, Choi YJ, Cheon MS, Kim YR. The New Treatment of Partial Unilateral Lentiginosis Using Dr. Hoon Hur's Golden Parameter Therapy With a High Fluence 1064nm Q-Switched Nd: YAG Laser Without Side Effects. Int J Cur Res. 2017; Decem: 9 (12): 63456-63460.

[18] Hur H, Park CH, Kim YR, Hyun DN. Treatment of Ota's Nevus Using Dr. Hoon Hur's Golden Parameter with a High Fluence 1064nm Nd: YAG Laser without Side Effects. J Dermatol Res and Ther. 2017; 3: 1-4.

[19] Hur H, Kim YR. The Treatment of Hori's Nevus by New Combination Treatment without Side Effects: Dr. Hoon Hur's Golden Parameter Therapy and Dr. Hoon Hur's Optimal Melanocytic Suicide-2 Parameter Therapy. J Clin Res Dermatol. 2017; 4: 1-5.

[20] Hur H, Park CH, Kim YR, Kim PS. Treatment of a Congenital Melanocytic Nevus by New Combination Therapy: Intense Pulse Light Therapy and Dr. Hoon Hur's Golden Parameter Therapy. J Dermatol Ther. 2017; 1: 12-16.

[21] Hur H, Lee GH, Kim PS, Hyun DN, Kim YR. The Treatment of Riehl's Melanosis Using Dr. Hoon Hur's Golden Parameter Therapy With a High Fluence 1064nm Q-Switched Nd: YAG Laser Without Side Effects. Int J Cur Res. 2018; Feb: 10 (2): 65103-65108. 
[22] Hur H, In SI, Cheon MS, Choi YJ, Lee DH, Kim YR. The Treatment of Erythema Ab Igne Using Dr. Hoon Hur's Golden Parameter Therapy With a High Fluence 1064nm QSwitched Nd: YAG Laser. Int J Cur Res. 2018; Oct: 10 (10): 74218-74221.
[23] Hur H, Shim DT, Cheon MS, Kim PS, Hyun DN, Kim YR. The Treatment of Postinflammatoty Hyperpigmentation Due To Prurigo Pigmentosa Using Dr. Hoon Hur's Golden Parameter Therapy With a High Fluence 1064nm Q-Switched Nd: YAG Laser. Int J Cur Res. 2019; Mar: 11 (3): 2491-2494. 